\title{
Funding Strategies for Emergency Medicine Research
}

\author{
Donna L. Carden, MD, Steven C. Dronen, MD, George Gehrig, MLIS, Robert J. Zalenski, MD
}

\begin{abstract}
- ABSTRACT
The importance of adequate funding for sustaining research efforts cannot be overemphasized. This article addresses funding strategies for emergency physicians, including the necessity of establishing a research track record, developing a well-written grant proposal, and anticipating the grant review process. Funding sources are reviewed with an emphasis on federal institute support and private foundations (including the Emergency Medicine Foundation) in the United States. Sources of current grant support information available from the Internet are provided. Recommendations for enhancing research funding in emergency medicine (EM) are made, including enhancement of formal research training, promotion of EM research and investigators, federal study section membership, and collaboration with established investigators.
\end{abstract}

Key words: emergency medicine research; research funding; foundation; extramural support.

Acad. Emerg. Med. 1998; 5:168-176.

I Sustained research efforts are not possible without adequate funding. In order to successfully compete for research funding, the investigator must accomplish several objectives. The most important objective is the establishment of a successful track record as a scientist. This is the only mechanism by which the investigator can establish a credible reputation with the scientists who will become the reviewers of future grant proposals and the best means to demonstrate competency to funding agencies.

\section{FUNDING STRATEGIES}

Establishing a Track Record: Acquiring expertise in a focused area of research is the first and most critical step to be taken by the investigator. Postgraduate research training with an established scientist is the conventional method of attaining such expertise. Formal research training allows the junior investigator to establish scientific credibility while gaining competency in a progressively focused area of study.

The second critical step to be accomplished by a successful scientist is the publication of investigations in order to demonstrate competency to peers and review committees. Such work demonstrates research expertise as well as skill in analysis and presentation of information. Review committees scrutinize the investigator's publication record as an indication of productivity and expertise.'

Acquisition of grant writing skills is another objective that must be accomplished in order to compete successfully for research funding. Care-

From the Louisiana State University Medical Center, Shreveport, LA, Departments of Emergency Medicine and Internal Medicine (DLC) and Department of Orthopedic Surgery (GG); University of Michigan, Ann Arbor, MI, Department of Emergency Medicine (SCD); and Wayne State University, Detroit, MI, Department of Emergency Medicine (RJZ).

Received: September 7, 1997; accepted: September 10, 1997.

Prior presentation: The Future of Emergency Medicine Research Conference, Washington, DC, March 1997.

Address for correspondence and reprints: Donna L. Carden, MD, Department of Emergency Medicine, LSU School of Medicine in Shreveport, 1501 Kings Highway, P.O. Box 33932, Shreveport, LA 71130-3932. Fax: 318-675-422J; e-mail: dcarden@www.ortho.lsumc.edu

This article is being copublished in Academic Emergency Medicine and the Annals of Emergency Medicine. 01998 Hanley \& Belfus, Inc. ful scrutiny of collaborators' funded proposals may assist the investigator develop these skills. In addition, copies of previously funded National Institutes of Health (NIH) grants can be obtained through the Freedom of Information Office at the NIH, but approximately 3 months from request are required to obtain these copies. Funded grants have also been published in journals, ${ }^{2}$ and there are other publications devoted to the subject of writing successful grant applications. ${ }^{2-6}$ In addition, common errors identified in unsuccessful proposals have been reported. ${ }^{2.5 .7-9} \mathrm{~A}$ well-written proposal is so critical to securing research funding that it is addressed separately.

Finally, emergency medicine (EM) researchers should consider establishing collaborative arrangements with established investigators in other university departments. ${ }^{10}$ In order to collaborate, one must have something to offer. The EM researcher has a significant resource to share since the emergency department (ED) is an excellent clinical arena for patient recruitment into a broad spectrum of studies. It is up to the EM investigator to know the ED population, how to recruit patients into clinical trials, and how to evaluate treatment outcomes. The EM researcher collaborating with a basic scientist not only may serve as an enthusiastic and energetic col- 
laborator but also may bring the necessary clinical perspective to a basic science question.

The Grant Proposal: The central doctrine of grantsmanship is that "The best writing can't turn a bad idea into a funded proposal, but bad writing can turn a good idea into an unfunded proposal." 6 It is worth the investigator's time to study references describing how to write a successful grant proposal ${ }^{2-6}$ or attend seminars on the subject.

Funded grant proposals are ones that are based on a novel, interesting, and well-defined problem for which the experienced investigator can suggest a feasible experimental plan. This plan must be part of a grant proposal that is clear, concise, consistent, and accurate. ${ }^{6}$ The investigator should be prepared to spend a substantial amount of time writing, revising, and rewriting the proposal in order to produce a document that is focused and clearly written. An experienced investigator (or several) should carefully critique the proposal to identify inconsistencies or areas that lack clarity.

It is important to contact the prospective funding agency well in advance of an application deadline in order to determine funding trends and review panel composition and eligibility requirements. The funding agency may provide the investigator with an example of a previously funded proposal and the program director or financial officer will be intimately familiar with the ageny's "mission." It is important to recognize that even a well-conceived and well-written proposal will not be funded if it does not match the agency's mission. Fortunately, it is often possible to write a proposal that is consistent with the agency's mission without compromising the investigator's research program.

The Grant Review Process: Evaluation of proposals is handled differently by various agencies but, in most cases, a scientific and tech- nical evaluation is accomplished by experts in the field of the proposal. For example, the NIH and the National Science Foundation (NSF) use the leading experts in the scientific community for extensive initial review of grant applications.

The investigator will have greater opportunity to obtain research funding if the unique review process of the agency that will judge his or her proposal is clearly understood. Most biomedical research funding is sponsored by the NIH. Consequently, this federal agency is one of the most competitive funding sources. In addition, university promotion and tenure are often based on an investigator's ability to secure extramural funding from agencies such as the NIH. Therefore, the grant review process of this agency is reviewed.

Grant applications submitted by the investigator to the NIH are received centrally in the Division of Research Grants (DRG). The applications are subjected to a stringent peer-review process based on 2 sequential levels of review, referred to as the "dual review system."

The first level of review involves groups of experts established according to scientific disciplines or research expertise to evaluate the scientific and technical merit of the grant. These panels are legislatively mandated and are referred to in DRG as study sections. Assignment of an application to a particular study section is based on the research topic and conformity to an Institute's mission. However, the investigator may request review by a specific study section at the time of the initial application. Only those proposals that are in approximately the top $50 \%$ of submitted applications for a particular review cycle will receive a priority score and be considered for funding.

National Institutes of Health study section membership is available on the Internet on the NIH home page free of charge. It is imperative that the investigator consider who will be reviewing his or her proposal in order to predict and address the concerns that are likely to arise in the review process.

The second level of review of applications submitted to the NIH is by a national advisory board or "Council," composed of both scientific and lay representatives. Council recommendations are based not only on considerations of scientific merit as judged by the study section, but also on the relevance of the proposed study to an Institute's programs and priorities. Assignment to an Institute is based on the Institute's legislatively mandated program responsibilities.

\section{FUNDING SOURCES}

Successfully competing for research money necessitates identifying sources of funding. In the past, identifying funding sources was difficult because all information was in print format. To access this information, a visit to a university main library or the library maintained by the university's grants office was necessary. With the advent of the Internet, its hypertext-linked, graphical component known as the World Wide Web (WWW), ${ }^{11.12}$ and the ability to publish and find documents electronically, identifying grant sources and information has become much more efficient.

Funding sources can be categorized as federal, foundations, corporate, state, or intramural. It is important to recognize that there are significant differences between the application processes for private and federal funds. For example, federal agencies usually have standardized application forms, whereas foundations tend to provide the investigator with general application guidelines, allowing more flexibility in the proposal. All federal grant opportunities are announced in advance, while material about foundations and corporate giving is often difficult to find.

Federal Funding: Some of the major federal sources of funding include 
the NIH, the NSF, the Department of Defense, the U.S. Department of Agriculture, the U.S. Department of Energy, the Agency for Health Care Policy and Research (AHCPR), the Centers for Disease Control and Prevention (CDC), and the Department of Veterans Affairs Medical Research Service (VAMR).

The NIH is a component of the U.S. Public Health Service of the Department of Health and Human Services, which funds biomedical and basic science research by administering funds made available through congressional appropriations. Most federally funded biomedical research is through the NIH. EM research may be appropriate for any of the 19 Institutes that comprise the NIH, depending on the research topic. ${ }^{\prime}$ Development of a successful track record and collaboration with established NIH scientists will assist the EM investigator in successfully competing for NIH funding.

The most common method of soliciting funds from the NIH is through the investigator-initiated RO1. The NIH also sponsors investigator-initiated programs designed to facilitate career development (K08, K12 awards) or to facilitate the transition from fellowship training to established investigator (R29 or First Award).

The AHCPR is the newest agency with organizational status equivalent to the Food and Drug Administration (FDA) or NIH. The AHCPR promotes the vision that the American health care system should provide high-quality, cost-effective services and improve health and the quality of life. The agency accomplishes this goal by: 1) collaborating with public and private partners to gather and disseminate impartial scientific information; 2) supporting and conducting health services research to guide improvements in both clinical care and the organization and financing of care; and 3) providing consumers, practitioners, and policy makers with the information and tools needed to make decisions about health care and health policy. The AHCPR plays a unique role as a source of unbiased information among competing interests in the health care industry. The AHCPR has funded outcomes-based research in injury, cardiac, and emergency medical services and is particularly interested in grants related to quality-of-care issues.

The CDC is a U.S. Public Health Service agency that directs a wide range of research programs encompassing the prevention and control of injuries, tobacco-related illness and other chronic diseases, environmental disasters, large-scale exposures to toxic substances, workplace hazards, emergencies arising from complex humanitarian disasters, and other major public health problems. Among the CDC's most important partners in accomplishing its mission are community and academic emergency physicians (EPs). Because of their clinical responsibilities, research priorities, and community orientation, EPs are strategically positioned to help the CDC identify public health problems, develop countermeasures, mobilize necessary efforts and resources, and ensure that necessary services are provided.

Emergency physicians can interact with the CDC by participating in extramural projects, serving on advisory and grant review committees, joining the 2-year Epidemic Intelligence Service (EIS) program, working part time on intramural projects, providing input on the agency's recommendations for preventing and controlling diseases and injuries, attending CDC-sponsored conferences, and communicating with appropriate agency staff when new public health problems or problem-solving opportunities are identified. The EIS is a 2year program in which participants receive epidemiologic training and provide epidemiologic services at a CDC program or in a state or local health department. Many EIS program graduates continue at the CDC in a staff position or pursue public health careers in other agencies. Elective rotations for EM residents also can be arranged by contacting specific intramural programs.

Extramural research opportunities are announced on the CDC's WWW home page (see below) and in the Federal Register. Most extramural funds are provided through individual research grants, cooperative agreements, and grants for research, program, and training centers. CDCsponsored conferences and the CDC's public health recommendations are announced in the Morbidity and Mortality Weekly Report (MMWR). The $M M W R$ also can be accessed electronically through the CDC's home page.

The VAMR has a long track record of funding clinically relevant research projects. Seed money can be promptly obtained for newly recruited VA clinician scientists. A 5/8 salaried appointment at a VA medical center is usually required for eligibility.

Each federal funding agency described above develops its own research initiatives or agenda. 'These initiatives originate from the interaction and scientific exchange of agency scientists with the biomedical community. EPs can become active participants in such groups by representing EM on task forces, in workshops, and in open agency meetings or by making their availability and expertise known to agency staff.'

Federal agencies support Instituteinititated projects in addition to investigator-initiated projects. Program announcements are released by an Institute or agency to identify broad areas of agency research interest that have not been assigned separate funding. An example is AHCPR's patient outcome and research team program announcement.

Requests for Applications (RFAs) are announcements of programs designed to meet a specific research need that is not met by investigatorinitiated research. An example of an RFA of particular interest to EM is the "Community Intervention to Re- 
duce Myocardial Infarction Delay.", The concept for this research initiative originated with the National Heart Attack Alert Program. The RFA was initiated because of the need for a large-scale study to evaluate the effect of public education on reducing the delay from onset of myocardial infarction (MI) symptoms until treatment of acute MI. Successful applications were those from investigators who had an established track record of research in the field of study, had assembled a multidisciplinary team, and submitted a well-written and detailed proposal. ${ }^{\prime}$

Requests for Proposals (RFPs) solicit applications from investigators to execute a research project that has been conceived, planned, and funded by the offering agency. Thus, the researcher takes the role of contractor delivering a service. Such work is a good place for the junior investigator to apply. A previous track record in research design, analysis, and publication is less important because the contractor is not required to perform these tasks. However, these contracts are competitive and demand adherence to the contract agreement.

There is also an announcement that is a hybrid of an RFA and an RFP, called a Cooperative Agreement. In the case of a Cooperative Agreement, the project specific aims have been formulated by the funding agency, but the research design, methods, and project execution are jointly performed by the investigator and the project officers.

Published documents as an information resource. A comprehensive list of funding opportunities from the federal government is contained in the Catalogue of Federal Domestic Assistance (CFDA). This reference text is available in most medical libraries. The Biomedical Index to Public Health Service-supported Research provides another means to determine which agency to approach with a grant proposal. It lists all grants and contracts awarded by the biomedical research programs

TABLE 1 Grant Web Sites (General)

\begin{tabular}{ll}
\hline \multicolumn{1}{c}{ Name } & \multicolumn{1}{c}{ URL } \\
\hline $\begin{array}{l}\text { University } \\
\text { Penn State University } \\
\text { University of Virginia-Charlottes- } \\
\text { ville }\end{array}$ & $\begin{array}{l}\text { http://infoserv.rttonet.psu.edu/gis } \\
\text { http://www.cs.virginia.edu/ seas/resdev/sponsors.html } \\
\text { Yale University }\end{array}$ \\
$\begin{array}{l}\text { Agttp://www.med.yale.edu/library/sir } \\
\begin{array}{l}\text { Community of Science } \\
\text { Department of Health and Human } \\
\text { Services }\end{array}\end{array}$ & $\begin{array}{l}\text { http://medoc.gdb.org/ } \\
\text { http://www.os.dhhs.gov/progorg/grantsnet/index.html }\end{array}$ \\
\hline
\end{tabular}

throughout the Department of Health and Human Services. The Federal Register is published each weekday and lists all federal program deadlines. Most federal and state agencies publish material that describes their research programs and specific application procedures. For example, The NIH publishes the NIH Guide for Grants and Contracts and the NSF publishes the Bulletin for this purpose. The Annual Register of Grant Support lists funding sources available through government agencies and includes information covered in the $C F D A$ as well as funding sources available through private foundations, industry, and professional sources. Another important source of information regarding funding is the agency credited with supporting the research in manuscripts or presentations at conferences. This is probably the most current information available to the astute observer regarding what agencies are funding specific fields of study.

While comprehensive, simply reading these sources discounts the fact that government programs are in a constant state of flux with changing funding levels, program status, and application procedures. Therefore, it is imperative that the investigator communicate directly with the scientific review administrator, program director, or giving officer of a particular agency prior to applying for grant support.

The Internet as an information resource. Web sites of major univer- sities, federal agencies, and organizations typically provide a web page with collective links to important grant sources, including sites that offer tips for writing grant proposals. Examples of these sites are listed in Table 1.

Of the university sites listed, the one at Penn State is of primary interest. The URL points to the GrantsWeb page. GrantsWeb is an excellent starting point for accessing grants-specific information and resources on the Internet. All 3 university sites provide links to both federal and nonfederal funding sources.

Specific grant sites may also be accessed directly (Table 2). The Federal Register is a free site which lists all federal program deadlines. DIALOG's Grants database is a commercial site that provides listings of thousands of grants and scholarships offered by federal, state, and local governments, commercial organizations, associations, and private foundations.

The Sponsored Programs Information Network (SPIN) is another database of funding opportunities (federal, nonfederal, and corporate) for faculty and institutional research, development, and educational programs. Federal Information Exchange (FEDIX) provides on-line information on grant and contract activity for several federal agencies and is available at no cost. The Catalog of Federal Domestic Assistance (CFDA) lists federal government loans and grants available. Entries cite agencies, 
- TABLE 2 Specific Federal Grant Web Sites

\begin{tabular}{ll}
\hline \multicolumn{1}{c}{ Name } & \multicolumn{1}{c}{ URL } \\
\hline Agency for Health Care Policy and Research & http://www.ahcpr.gov \\
Centers for Disease Control and Prevention & http://www.cdc.gov/ \\
CFDA & gopher://solar.rtd.utk.edw/11/Federal/CFDA \\
CRISP & http://www.nih.gov/grants/award/crisp.htm \\
Department of Defense Technical Information & http://www.ilcoalition.org/dtic.htm \\
$\quad$ Center & http://www.va.gov/ \\
Department of Veterans Affairs & http://www.dialog.com/ \\
DIALOG & http://www.access.gpo.gov/su_docs/aces/ \\
Federal Register & aaces002.html \\
& http://web.fie.com/ \\
FEDIX & http://www.nih.gov/ \\
National Institutes of Health & http://www.nsf.gov/ \\
National Science Foundation & gopher://gopher.nih.gov:70/11/res/nih-guide \\
NIH Guide & Send request to:grants-request@ @ns.gov \\
NSF Bullețin Mailing list & gopher://spin.infoed.org:70/11/ \\
SPIN & SPIN\%20USA \\
& http://www.usda.gov/ \\
U.S. Department of Agriculture & http://www.doe.gov/ \\
U.S. Department of Energy &
\end{tabular}

program objectives, types of assistance available, eligibility, application procedures, contacts and sources of information, and examples of funded projects. CRISP is a biomedical database containing information on research supported by the U.S. Public Health Service. Most of this research falls within the broad category of extramural projects, but CRISP also contains information on intramural research programs of the NIH and FDA.

Foundations: Due to the recent decline in federal funding of biomedical research, the investigator may find it beneficial to look to foundations as a source of research funding. A private foundation is a nongovernmental, nonprofit organization. Unlike the federal government, which generates a constant stream of funding announcements, foundations do not usually issue lists of grants to be awarded. Finding appropriate foundations for research funding is not an easy task.

Published documents as an information resource. The Foundation Center, located in New York City, collects information on private foundations and then distributes this information through its publications and library collections. The Foundation Center's most useful tool for identifying nonfederal sources of research support is the Foundation Directory. ${ }^{13}$ This directory outlines approximately 3,000 of the largest foundations and includes application information on the number and kind of grants available from each source. The Foundation Center also publishes the Foundation Grants Index and Source Book Profiles, which not only provide extensive coverage of foundations but are particularly useful in identifying smaller, local organizations with interest in supporting research.

The Internet as an information resource. Specific nonprofit organizations have sites that may be accessed directly (Table 3). The Foundation Directory and the Foundation Grants Index can be searched on DIALOG (Table 2). In addition, Foundations On-Line provides extensive coverage of nongovernmental sources of research funding.

The Emergency Medicine Foundation (EMF) is a funding source designed to advance the scientific knowledge base of emergency medicine and, therefore, this foundation is described separately.

Emergency Medicine Founda- tion. The EMF awards fill a valuable role within the specialty; these awards support the development of young faculty or, in the case of the Center of Excellence Grant, developing research programs. Grants are offered to support academic development at all levels from medical student through faculty. It is possible to receive funding from the EMF at several stages in the EM investigator's career, thereby facilitating development of a solid and credible track record that will increase competitiveness with traditional funding agencies. Ten categories of awards are offered annually by the EMF, ranging in amount from $\$ 2,400$ to $\$ 250,000$. The majority are small project grants of approximately $\$ 5,000$. Larger awards include the $\$ 25,000$ Research Fellowship and Career Development Grants, the $\$ 75,000$ Cardiovascular Research Grant (instituted in 1995), and the $\$ 250,000$ Center of Excellence Award (instituted in 1993).

Although limited in size and number, the EMF awards offer a number of advantages to the EM investigator. First, because recipients are limited to the EM community, the number of applicants is fairly small, and a wellwritten application has a good chance of success. A second advantage is that the focus of many of these awards is on training, which clearly addresses a major need of the specialty. There is an expectation that research supported by EMF will be conducted in a rich academic environment that has appropriate educational resources and will expose the recipients to qualified mentors. Because the focus is on training, there is less emphasis on the quality of the science described and on the previous track record of the applicant than may be found with other funding agencies. This is likely to change, however, as the EM research community becomes more sophisticated.

A significant disadvantage of the EMF awards is their small dollar value. None of the EMF awards, with perhaps the exception of the Center 
of Excellence Award, is of sufficient size to fully fund a laboratory or provide substantial faculty salary support. For many of the grants, applicants must seriously consider whether the size of the grant is sufficient to justify the time spent writing it.

Individuals applying for EMF funding for the first time often choose the Resident Research Award. The EMF provides approximately 4 of these per year at $\$ 5,000$ each. This amount is adequate to provide partial funding for a laboratory project of limited scope or to support the costs associated with patient enrollment and data collection for a clinical project. The grant is not intended to fund capital expenditures and is insufficient to fund laboratory start-up costs. Therefore, it is best used as a mechanism to involve residents in well-established, productive research programs. Often this can be accomplished by having a resident develop a satellite project related to the overall body of work of the research mentor. Although writing this grant is not difficult or time-consuming, the amount awarded does not justify a major investment of faculty time. Ideally, the grant should be written by the resident who is the intended recipient of the award in order to introduce that individual to basic grantwriting skills and to ensure complete familiarity with the proposed project. The writing should be done in close association with the faculty member who will serve as the resident's research mentor.

The EMF Research Fellowship Grant (currently $\$ 25,000$ for 1 year) is intended to provide support to an EM residency graduate who has committed 1-2 years to the development of research skills. Therefore it is a training grant and in order to be successful, an application should place high priority on the quality of the fellow's educational experience. Time spent in the laboratory, no matter what the quality of the experience, is not sufficient. At a minimum the training program should include reg-

TABLE 3 Non-federal Sources of Funding on the Internet

\begin{tabular}{ll}
\hline \multicolumn{1}{c}{ Name } & \multicolumn{1}{c}{ URL } \\
\hline Emergency Medicine Research Database & http://smi.bih.harvard.edu/SAEM/EMRDB.html \\
Carnegie Mellon Foundation & http:/www.carnegie.org/ \\
Charles Dana Foundation & http://www.dana.org/ \\
Foundation Center & http://fdncenter.org/ \\
Foundations On-Line & http://www.foundations.org/ \\
\hline
\end{tabular}

ular coursework in areas such as statistics, grant writing, medical writing, and epidemiology; participation in all phases of a high-quality research project from planning through publication; opportunities for writing in the medical literature and critically evaluating others' writing; participation in the institutional review board (IRB) process; and most importantly, significant exposure to successful and productive researchers both within and outside the specialty. Given the broad scope of the training involved, a 2year period of training is preferred. Although awards are for 1 year, reapplications are considered for a second year of support.

The EMF Career Development Award is similar in purpose to the Research Fellowship Grant, but it is awarded to EM faculty at the instructor or assistant professor level. An applicant for this award should have already developed at least a limited track record as a successful researcher and should be in an environment that will foster continued academic development. The award is intended to provide resources in the form of either project funding or salary support that will allow junior faculty to pursue a promising research question. Compared with the Research Fellowship Award, the EMF Career Development Award places more emphasis on the likelihood that the award will enhance the investigator's national competitiveness. The training portion of the program should therefore be individualized to reflect the applicant's strengths and weaknesses. A critical element of this application is the choice of the applicant's preceptor(s). This individual must understand that his or her role is to oversee the de- velopment of a junior faculty into a competent researcher who will be able to compete successfully for future research funding. Therefore, a preceptor should be chosen who has a proven track record as a researcher, experience mentoring residents and faculty, and the time and energy needed to participate regularly in the applicant's career development.

The EMF Center of Excellence Grant is a 3-year, $\$ 250,000$ award that is intended to support development of a research program and its faculty. Key elements of a successful application include: 1) a significant emphasis on the training of fellows and faculty, 2) focus on an area of scientific investigation that is likely to lead to extramural funding, and 3) collaborations with seasoned investigators who will contribute to the quality and complexity of the scientific endeavor and will serve as mentors to junior investigators. $\$ 25,000$ per year of this award is earmarked for research fellow training and therefore all the critical features mentioned above for the Research Fellowship Grant should be included. In addition. because a developing research program generally involves the participation of one or more junior faculty, the application must explain how the award will contribute to their academic development. Finally, the importance of collaboration with funded researchers in other departments in the institution cannot be overemphasized.

Industry/Corporate Sponsors: The decline in federal funding for biomedical research in recent years has made it increasingly difficult for junior investigators to compete success- 
fully for this important source of funding. Simultaneously, there has been an increase in pharmaceutical firm sponsorship of controlled clinical trials with the goal of bringing new drugs and products to the market. Therefore, it may be productive for an investigator to look to industry as a source of research dollars.

In order to be a potential collaborator with a corporate sponsor, a principal investigator must have an accurate knowledge of the population to be enrolled in the clinical trial, have access to an adequate number of patients eligible for study entry, be able to enroll patients in a timely fashion, and meticulously complete required data forms. The investigator should also be aware that a research nurse and pharmacist are integral components of a research team and these individuals are critical to the overall success of a clinical trial. In addition, sponsors expect investigators to have a site study coordinator who can assist with study implementation, patient recruitment, chart review, and report completion. ${ }^{14}$ It is desirable, but not necessary, that the principal investigator have prior experience with clinical trials since the sponsor needs assurance of a successfully completed trial. Finally, corporate sponsors may also wish to collaborate with an investigator at a site whose IRB meets frequently and has a reasonable turnaround time for protocols.

The agency responsible for regulations and guidelines governing the conduct and supervision of clinical trials in the United States is the FDA. Although it is the corporate sponsor's responsibility to communicate with the FDA and to provide complete information on the protocol design, study conduct, and the experience of the patients exposed to a study drug, the principal investigator must also be aware of the FDA regulations and guidelines. For example, these regulations state that the investigator must maintain adequate and accurate records of all observations on all pa- tients. The FDA requires that the industry sponsor visit each site to review drug accountability, regulatory documentation, and the medical records of each subject enrolled in the clinical trial, but the FDA also may elect to audit the study site.

Regulatory documents required for implementation of clinical trials include the Statement of Investigator, which delineates the name, address, education, and training of the principal investigator, the names of all coinvestigators, study location, and confirmation of IRB approval. Case report forms are used to collect data on patient demographics. Serious adverse patient events (SAEs) are reported on a standardized SAE form, which must be reported by the sponsor to the FDA in a timely fashion. ${ }^{15}$

Prior to establishing a collaborative interaction with an industry sponsor, the investigator should recognize the potentially conflicting goals of industry and investigator. For example, industry has an interest in publishing mainly positive results, bringing new products to market quickly to minimize patent limitations, and earning a profit for shareholders. An initial awareness of the sponsor's objectives allows the investigator to establish an agreement that eliminates potential conflicts. Such an agreement should be formalized before the start of a clinical trial and should address issues such as: 1) access to data; 2) right to publication of all or parts of collected data; 3) indications for project termination; and 4) access to all publications resulting from the research to ensure that data collected will not be cited out of context. ${ }^{14.16}$ If the objectives of the sponsor and investigator are clearly delineated prior to study initiation, this type of collaborative arrangement may be beneficial to the company sponsoring the research, the investigator, and ultimately the public.

Intramural Funding: It is important that the EM investigator thoroughly explore intramural funding opportunities at his or her university or institution. These awards are usually of limited monetary value and are designed to allow junior faculty to generate preliminary data to enhance their national competitiveness or to sustain an investigator if a previously funded grant is not renewed. Offsetting the limited monetary value of these awards is the fact that the competition for these grants is confined to the university's faculty. Thus, not only are intramural awards a likely source of seed money for the junior investigator, but the application process familiarizes faculty in other departments with the research efforts of the EM investigator and may facilitate future collaborative arrangements.

\section{RECOMMENDATIONS}

Research Training: Since acquiring expertise in a focused area of research is the critical step to be achieved by a successful investigator, EM must determine mechanisms to enhance research training of its investigators.

1. The number of EM fellows who remain associated with academic programs after completion of a research fellowship that follows clinical training has been disappointing (Krause G, 1995 report of ACEP Scientific Review Panel). An alternative to the traditional EM research fellowship is the establishment of funding for research training of EM residents. It is not uncommon for residencies at major universities in other disciplines to interrupt clinical training in order to dedicate a minimum of 1 year to research training. ${ }^{17}$ Thus, funding dedicated to the training of promising mid-level EM residents within the laboratories of established, federally funded investigators, at research institutes (NIH, CDC) or programs such as the EIS offered by the CDC should be considered. 
2. As suggested by Kelen and Brown, ${ }^{17} \mathrm{EM}$ research fellowships should be modeled after traditional fellowships and designed to allow the physician to attain a $\mathrm{PhD}$, $\mathrm{MPH}$, or similar degree. The rigorous demands of these programs are likely to attract the most serious physician scientists. Similarly, EM departments, the EMF, the American College of Emergency Physicians (ACEP), and/or the Society for Academic Emergency Medicine (SAEM) should consider sponsoring NIH fellowships or fellowships with established investigators at major research institutes.

3. Research training fellowships should be developed for investigators at the junior faculty level. Unlike the traditional method of funding in which an investigator develops a proposal that is reviewed for funding, these fellowships should fund the training of promising junior faculty within the laboratories of established and federally funded scientists or at recognized research institutes. This mechanism will permit EM investigators to learn from leading experts in the scientific community, will expand the scientific methodology used in EM research, and will familiarize EM researchers with established investigators in their field of study.

4. Established, intensive courses in research training such as the one at Woods Hole, MA, are designed to permit the investigator with prior experience gain additional training in state-of-the-art methods and research strategies. Thus, research training fellowships at established settings should be competitively offered to senior EM research faculty.

\section{Promotion of EM Research and In- vestigators:}

1. The establishment of symposia designed to facilitate the interaction of EPs with federal funding agency officials should be considered. EPs can become active participants in the establishment of federal funding agency initiatives by representing EM on task forces, in workshops, and in open meetings or by making their availability and expertise known to agency staff.' The participation of EM investigators in defining agency initiatives may be facilitated by allowing agency officials to become familiar with EPs and the health care issues relevant to EM.

2. Established, federally funded investigators or consultants should be considered as speakers for the SAEM annual meeting, or the ACEP scientific assembly or research forum.

Study Section Membership: Members of NIH study sections and review committees have established a record of success in research and have usually been successful in obtaining NIH funding. EPs who have established research track records can and should request consideration as an NIH study section member. Such participation may facilitate increased recognition by the scientific community and reviewing agencies on the importance and relevance of research issues critical to EM.

EMF Awards: A comprehensive evaluation of the impact of the EMF Awards on the academic development of awardees was completed in 1995 by the ACEP Scientific Review Panel. The grants that had a measurable impact on the careers of EM investigators were the Research Fellowship Award and the Career Development Award. Only the Career Development Award had a measurable effect on the competitiveness of awardees, but this enhanced competitiveness required 3 years to achieve (personal communication, Gary Krause, MD, past Chairman, ACEP Scientific Review Panel, 1995). Thus, it may be worthwhile to consider decreasing the number of small awards in lieu of Career Development Awards of greater duration and monetary value.

\section{Collaboration with Established In- vestigators:}

1. Collaborative research with experts in other fields not only assists academic EPs develop appropriate skills, but also enhances their competitiveness with outside funding agencies. ${ }^{10}$ Thus, collaboration of EM investigators with established investigators in other disciplines should be encouraged. It also may be beneficial to recruit established, nonphysician investigators for research positions in academic EDs. Finally, EDs may increase the number of adjunct faculty positions offered to investigators in other disciplines or university departments.

2. The Interactive Research Project Grant (IRPG) program announced in the NIH Guide for Grants and Contracts (Vol. 21, No. 16, April 23,1993 ) provides support for formal, investigator-initiated, collaborative relationships. An IRPG group consists of the coordinated submission of $\geq 2$ applications for related research project grants that do not require extensive shared physical resources. Thus, the IRPG award may eliminate the need for junior faculty to identify a mentor at their own institution and may facilitate a formal collaborative arrangement between experienced EM investigators in different institutions.

The authors acknowledge the contribution of Daniel Pollack, MD, Division of Acute Care Rehabilitation Research and Disability Prevention, National Center for Injury Prevention and Control, at the CDC for his contribution of information on emergency medicine funding opportunities at the CDC. In addition, the authors thank Alex Ommaya, ScD, Senior Policy Analyst, Agency for Health Care Policy and Research, for information on funding opportunities at the AHCPR. 


\section{REFERENCES}

1. Simons-Morton DG Funding avenues for research in emergency medicine at the $\mathrm{Na}$ tional Institutes of Health and the National Heart, Lung, and Blood Institute [commentary]. Acad Emerg Med. 1996; 3:202-4.

2. Eaves GN, Pike JM, Bernard SC. A successful grant application to the National Institutes of Health: case history. Grants Magazine 1978; 1(3):263-8.

3. Adelstein SJ. Preparing a grant proposal. Invest Radiol. 1993; 28:110-2.

4. Alazraki NP. The Grantsmanship Workshop 1986-1992 and radiology research funding. Invest Radiol. 1993; 28(suppl 2):S6-S9.

5. Gordon SL. Ingredients of a successful grant application to the National Institutes of Health. J Orthop Res. 1989; 7:138-41.

6. Reif-Lehrer L. Writing a Successful Grant
Application. Boston: Jones and Barlett, 1989. 7. Allen EM. Why are research grant applications disapproved? Science. 1960; 132: 1532-4.

8. Cuca JM. NIH grant applications for clinical research: reasons for poor ratings. Clin Res. 1983; 31:453-61.

9. Cuca JM, McLoughlin WJ. Why clinical research grant applications fare poorly in review and how to recover. Cancer Invest. 1987; 5: 55-8.

10. Lewis LM, Callaham ML, Kellermann AL, Marx JA, White JD. Collaboration in emergency medicine research: a consensus statement. Acad Emerg Med. 1998; 5:1526.

11. McKinney WP, Wagner JM, Bunton G, Kirk LM. A Guide to Mosaic and the World Wide Web for physicians. MD Comput 1995; 12:109-14, 141 .
12. Pallen $M$. The World Wide Web. Br Med J. 1995; 311: 1552-6.

13. Locke LF, Spirduso WW, Silverman SJ. Proposals That Work. Newbury Park, CA: Sage Publications, 1987, pp. 112-15.

14. Lewis RH. Working with industry. Ann Emerg Med. 1996; 27:414-5.

15. Kessler DA. The regulation of investigational drugs. $N$ Engl J Med. 1989; 320: 281-8.

16. Paris PM: Relationship between academia and industry: ethical considerations. Ann Emerg Med. 1996; 27:416-7.

17. Kelen GD, Brown CG. The future of emergency medicine research. In: The Role of Emergency Medicine in the Future of American Medical Care: Proceedings of a Conference Chaired by $L$. Thompson Bowles, MD, PhD. Josiah Macy Jr Foundation, 1995, pp. 173-93. 